\title{
Two new species of Oreocharis (Gesneriaceae) from karst regions in Yunnan and notes on O. tetraptera and $O$. brachypoda from China
}

\author{
Lei Cai', Zhang-Jie Huang ${ }^{2,3}$, Fang Wen ${ }^{2,3}$, Zhi-Ling Dao'
}

I Yunnan Key Laboratory for Integrative Conservation of Plant Species with Extremely Small Populations, and Key Laboratory for Plant Diversity and Biogeography of East Asia, Kunming Institute of Botany, Chinese Academy of Sciences, Kunming 650201, Yunnan, China 2 Guangxi Key Laboratory of Plant Conservation and Restoration Ecology in Karst Terrain, Guangxi Institute of Botany, Guangxi Zhuang Autonomous Region and Chinese Academy of Sciences, Guilin 541006, Guangxi, China 3 Gesneriad Conservation Center of China, Guilin Botanical Garden, Chinese Academy of Sciences, Guilin 541006, Guangxi, China

Corresponding author: Fang Wen (wenfang760608@139.com), Zhi-Ling Dao (daozhl@mail.kib.ac.cn)

Academic editor: Eric Roalson | Received 18 March 2020 | Accepted 24 July 2020 | Published 7 October 2020

Citation: Cai L, Huang Z-J, Wen F, Dao Z-L (2020) Two new species of Oreocharis (Gesneriaceae) from karst regions in Yunnan and notes on O. tetraptera and O. brachypoda from China. PhytoKeys 162: 1-12. https://doi.org/10.3897/ phytokeys. 162.52174

\begin{abstract}
Two new species of Gesneriaceae, Oreocharis aimodisca and O. longipedicellata, from the limestone area of Yunnan Province, China, are described and illustrated. Their morphological relationship with similar species is discussed and colour photographs, detailed descriptions, distribution and habitat, as well as the IUCN endangered status are provided. We also discuss the accuracy of the scientific names of the described species O. tetrapterus from Guangxi, China in 2019 and O. brachypodus from Guizhou, China, in 2015, and put forward corrections related to name form.
\end{abstract}

\section{Keywords}

flora of Yunnan, limestone area, morphology, new taxon, Oreocharis

\section{Introduction}

At least 30 new taxa of Oreocharis Benth. (Gesneriaceae) have been described and officially published (e.g., Cai et al. 2017, 2019; Do et al. 2017; Chen et al. 2018; Guo et al. 2018; Möller et al. 2018; Pan et al. 2019; Yang et al. 2019) after the generic

Copyright Lei Cai et al. This is an open access article distributed under the terms of the Creative Commons Attribution License (CC BY 4.0), which permits unrestricted use, distribution, and reproduction in any medium, provided the original author and source are credited. 
redefinition based on new evidence following the development of molecular phylogenetics in 2011 (Möller et al. 2011) and several later adjustments of the species (Middleton et al. 2013; Chen et al. 2014; Möller et al. 2014; Möller 2015). Oreocharis s.l. hitherto comprises more than 140 taxa, mainly distributed in South and Southwest China (Wen et al. 2014, 2019) and a few species extending into North Vietnam (nine species), Myanmar (two species), Bhutan (one species), India (one species), Japan (one species) and Thailand (one species) (Xuyen et al. 2016; Do et al. 2017; Möller et al. 2017, 2018; Chen et al. 2018).

$\mathrm{Li}$ and Li (2015) and Pan et al. (2019) each described new species of Oreocharis. One of the taxa with four corolla lobes is from Guangxi, China, which they named O. tetrapterus F.Wen, B.Pan \& T.V.Do (Pan et al. 2019). The other has sessile or shorter petiole leaves and four stamens with anthers coherent in pairs from Guizhou, China, which was named as O. brachypodus J.M. Li \& Z.M. Li ( $\mathrm{Li}$ and Li 2015). These scientific names are improperly formed because the Latin forms 'tetrapterous' and 'brachypodus' are masculine and the Latin word of this genus, 'Oreocharis', is feminine. We revise the Latin name to 'tetraptera' and 'brachypoda' here and provide appropriate notes.

In 2018, during field investigations in the limestone area in Southeast Yunnan, China, an unknown species of Gesneriaceae without flowers was collected, then was introduced to, and cultivated in, Guilin Botanical Garden (GBG). We first observed flowering plants which were cultivated in GBG in August 2019. Thereafter, in September 2019, another unknown species of Gesneriaceae with flowers was collected from Shizong County, eastern Yunnan. We confirmed that they are both members of Oreocharis, based on the characteristics of leaves in a basal rosette, four separated fertile stamens and capsules dehiscing predominantly on one side. After a careful examination of the related specimens and taxonomic publications of Oreocharis from the adjacent regions (Wang et al. 1990, 1998; Li and Wang 2005), we concluded that these two species are both new to science. Here, Oreocharis aimodisca and $O$. longipedicellata are described and illustrated and their morphological characters are compared to closely-related species.

\section{Material and methods}

Extensive fieldwork has been undertaken in the east and southeast of Yunnan, China, in recent years. Samples of the two new species were respectively collected from the fields of Shizong County and living plants cultivated in Guilin Botanical Garden (GBG) which initially introduced from Malipo County, Yunnan, China. All available specimens of Oreocharis s.l., stored in herbaria (E, HITBC, IBK, HN, K, KUN, P, PE and VMN), Chinese Virtual Herbarium (http://www.cvh.ac.cn/) in China and Global Plants on JSTOR (https://plants.jstor.org/) were examined. We studied all morphological characters with dissecting microscopes and described the morphological characters by using the terminology presented by Wang et al. $(1990,1998)$. The photographs and the specimens were taken in the field and GBG by the first and correspondence authors. All specimens seen are indicated by '?'. 


\section{Taxonomic treatment}

\section{Oreocharis tetraptera F.Wen, B.Pan \& T.V.Do}

Orthographic variant. Oreocharis tetrapterus F.Wen, B.Pan \& T.V.Do in Pan et al. 2019: 83.

Type. China. Guangxi: Hezhou City, Lisong Town, Gupo Mountain, 24³9'N, $111^{\circ} 36^{\prime} \mathrm{E}$, elev. ca. $950 \mathrm{~m}$, on moist surface of granite rocks, in flower, 25 August 2018, Wen Fang WF160825-01 (holotype: IBK!, isotype: IBK!).

\section{Oreocharis brachypoda J.M. Li \& Z.M. Li}

Orthographic variant. Oreocharis brachypodus J.M. Li \& Z.M. Li in Li and Li 2015: 296.

Type. China. Guizhou: in the vicinity of Tongren city, on rather cool rocks and very steep banks of cool, clammy soil that grows a fine film of moss, elev. 1300 m, 9 April 2014, Jia-Mei Li 2304 (holotype: HEAC!); ibid. Jia-Mei Li 2305 (paratype: HEAC!).

Notes. The gender of the genus name, Oreocharis, is feminine, but the suffix of the scientific name, "-us," is typically masculine. For Oreocharis tetrapterus (Pan et al. 2019), the correct orthography of the name of the new species is $O$. tetraptera, is written by using an inaccurate gender, namely "tetrapterus", in the citation of the type of the new species (p. 85), in the discussion of the Etymology (p. 86) and in the notes of the illustration (pp. 86, 87 and 88). In the other new taxon, Oreocharis brachypodus ( $\mathrm{Li}$ and Li 2015), the correct orthography of the epithet "brachypoda" should be used to replace "brachypodus". The inaccurately-used name gender appeared in the citation of the type of the new species (p. 296) and in the notes of the illustration (pp. 297 and 298). Thus, here we correct and revise two new species' names as Oreocharis tetraptera and $O$. brachypoda.

\section{Oreocharis aimodisca Lei Cai, Z.L.Dao \& F.Wen, sp. nov.} urn:Isid:ipni.org:names:77211926-1

Figures 1-3

Diagnosis. Oreocharis aimodisca is morphologically similar to O. longifolia (Craib) Mich.Möller \& A.Weber and O. muscicola (Diels) Mich.Möller \& A.Weber in the appearance and colour of its flowers, but differs from the latter two species in its leaf blade oval to ovate, base cordate or auriculate, margin crenate, peduncle densely brown villous and pubescent, corolla outside densely pubescent and four separated fertile stamens, pistil densely pubescent and disc blood red.

Type. China. Yunnan: Shizong County, Wulong Town, Dachang Village, Xiaofakuai, $24^{\circ} 39^{\prime} \mathrm{N}, 104^{\circ} 10^{\prime} \mathrm{E}$, elev. ca. $2122 \mathrm{~m}$, on the surface of wet rocks, in flower, 10 September 2019, Lei Cai \& Pin Zhang CL275 (holotype: KUN!, isotypes: KUN!, IBK!). 


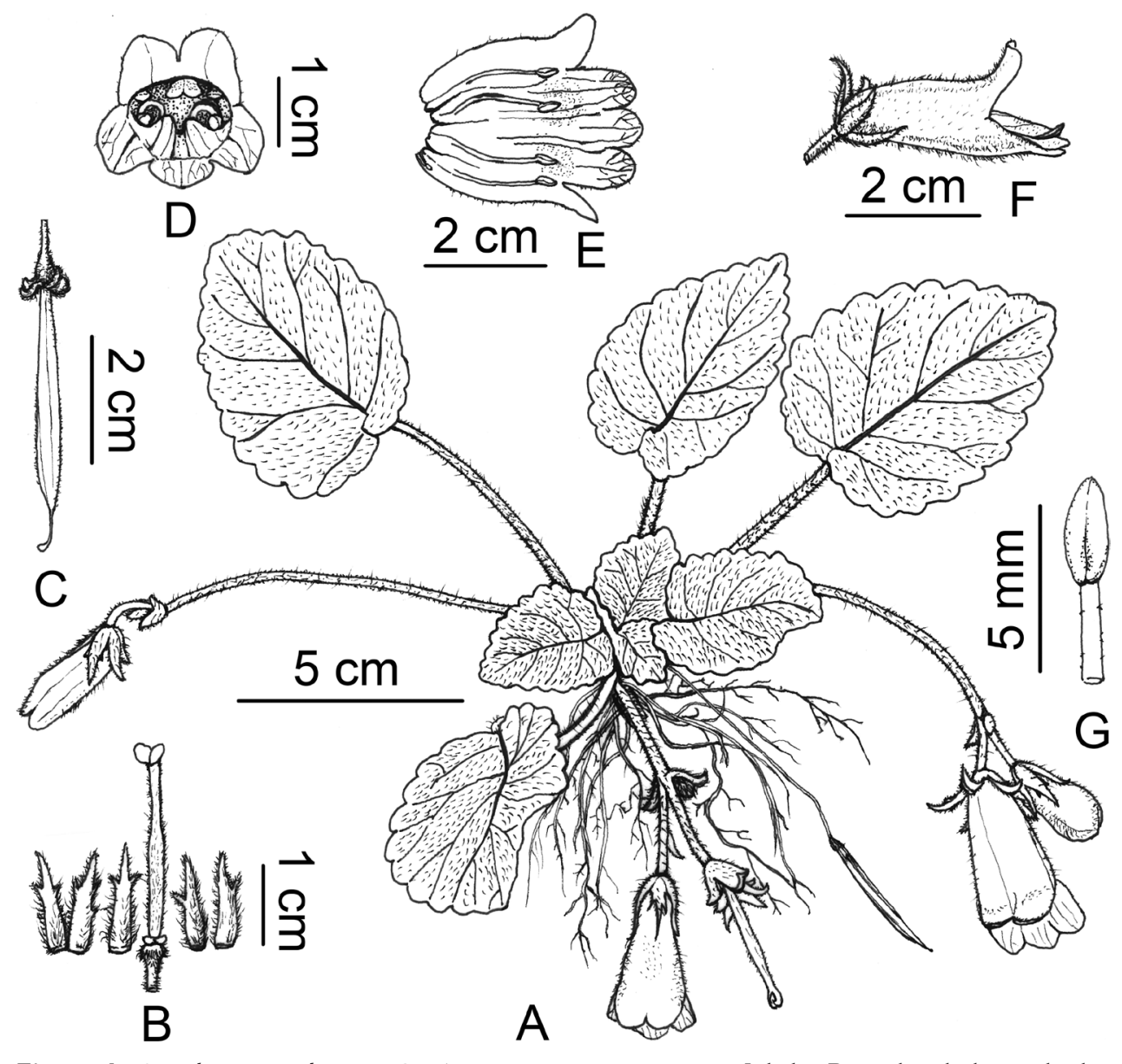

Figure I. Oreocharis aimodisca Lei Cai, Z.L.Dao \& F.Wen, sp. nov. A habit B pistil with disc and calyx $\mathbf{C}$ old capsule $\mathbf{D}$ front view of flower $\mathbf{E}$ opened corolla showing stamens and staminode $\mathbf{F}$ side view of a flower $\mathbf{G}$ adaxial view of the anther. Drawn by Xuan-Lin Zhu.

Description. Perennial herb, rhizome 5-18 $\mathrm{mm}$ long, 3-5 $\mathrm{mm}$ in diameter. Leaves 6-18, basal, petiole $2.5-10.5 \mathrm{~cm}$ long, brown villous and pubescent, leaf blade oval to ovate, $2.5-7.0 \times 1.8-5.5 \mathrm{~cm}$, adaxially densely appressed pubescent, abaxially puberulent, densely brown pubescent along veins, lateral veins 3-6 on each side of midrib, adaxially inconspicuous, abaxially conspicuous, apex acute, base cordate or auriculate, slightly oblique sometimes, margin crenate. Cymes axillary 2-5, inflorescence 1-5-flowered; peduncle 5.5-16 cm long, brown villous and pubescent; bracts 2 , lanceolate to narrowly triangle, $5-8 \times 1.5-2.8 \mathrm{~mm}$, outside brown pubescent, inside glabrous, margin nearly entire to denticulate; pedicel $1.2-3.5 \mathrm{~cm}$ long, densely pubescent. Calyx $8-12 \mathrm{~mm}$ long, 5-lobed to the base, lobes unequal, linear-lanceolate or narrowly triangular, $8-12 \times 1.5-2.2 \mathrm{~mm}$, both sides densely pubescent, margin denticulate. Corolla yellow, $2.8-3.6 \mathrm{~cm}$ long, out- 

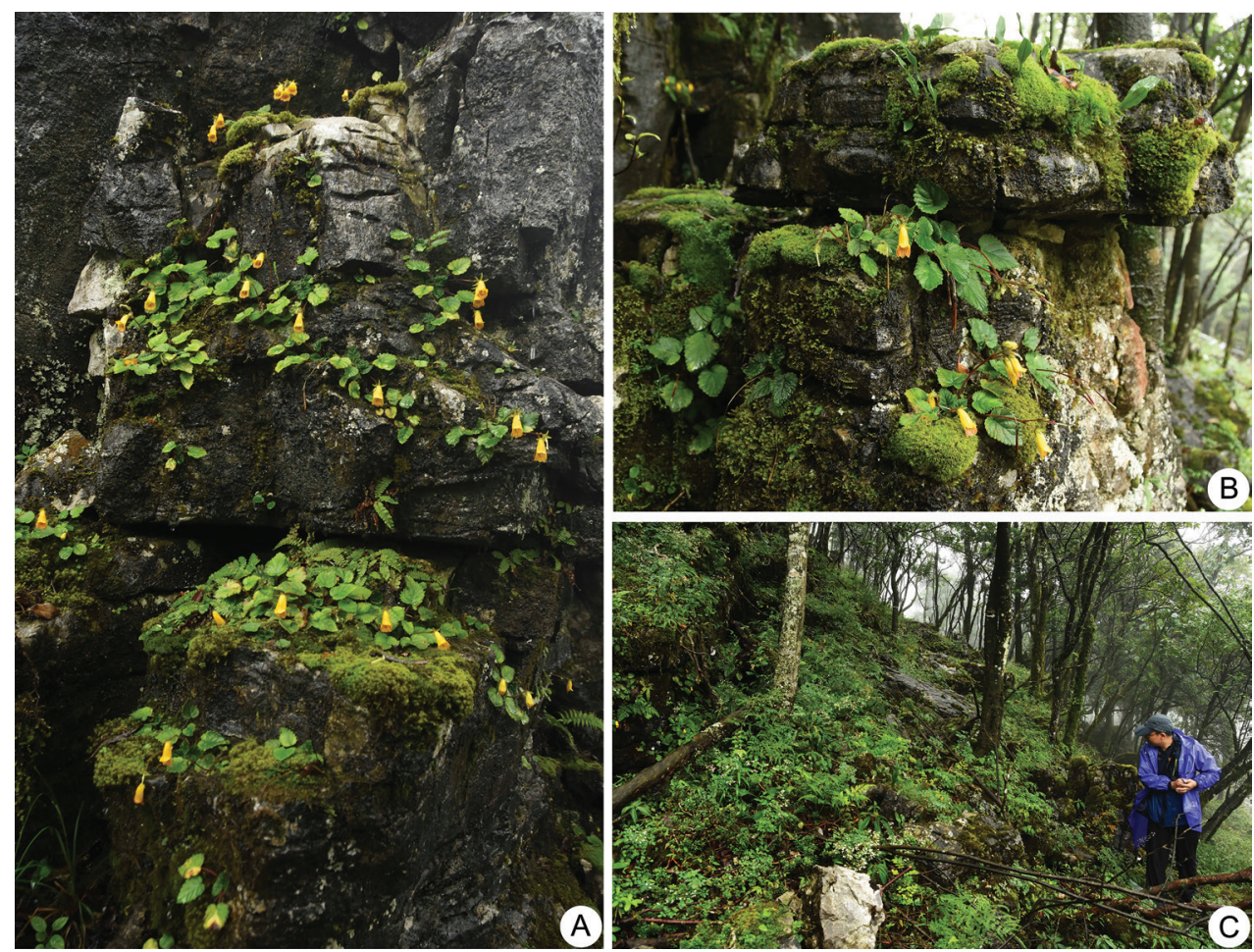

Figure 2. Oreocharis aimodisca Lei Cai, Z.L.Dao \& F.Wen, sp. nov. in natural habitat A, B plants with flowers in the wild $\mathbf{C}$ habitat. Photographed by Lei Cai.

side densely pubescent, inside puberulent in the throat and on adaxial lobes, the lower part forms red stripes on the throat and lobes, tube coarsely tubular, gradually expanded from base to the throat, $2.0-2.6 \mathrm{~cm}$ long, 6-10 $\mathrm{mm}$ in diameter; limb 2-lipped; adaxial lip 2-lobed to middle, semicircular, lobes 4-5 $\times 4-5 \mathrm{~mm}$, abaxial lip 3-lobed to middle, semicircular, 5-6 × 5-7 mm. Stamens 4, 1.5-1.8 cm long, adnate to corolla $4-7 \mathrm{~mm}$ from the base; filaments linear, sparsely pubescent; anthers oblong, 2-loculed, dehiscing longitudinally, connective glabrous; staminode 1, 0.6-0.8 mm long, inserted ca. $3 \mathrm{~mm}$ from the base. Disc ca. $1.2 \mathrm{~mm}$ high, blood red, margin undulate. Pistil 1.6-2.4 cm long; ovary long cylindrical, densely pubescent, 1.0-1.4 cm long; style 6-10 mm long, densely pubescent; stigma bilobed, flabellate. Capsule linear, 3.5-4.8 cm long.

Phenology. Flowering from August to September; fruiting from September to December.

Distribution and habitat. Oreocharis aimodisca is currently known from two adjacent populations at the type locality, Shizong County, East Yunnan, China. The new species commonly growing with other plants in shady and wet places on the middle part of mountain slopes under primary evergreen broad-leaf forest and shrubbery on karstic limestone at an elevation of over $2000 \mathrm{~m}$. 


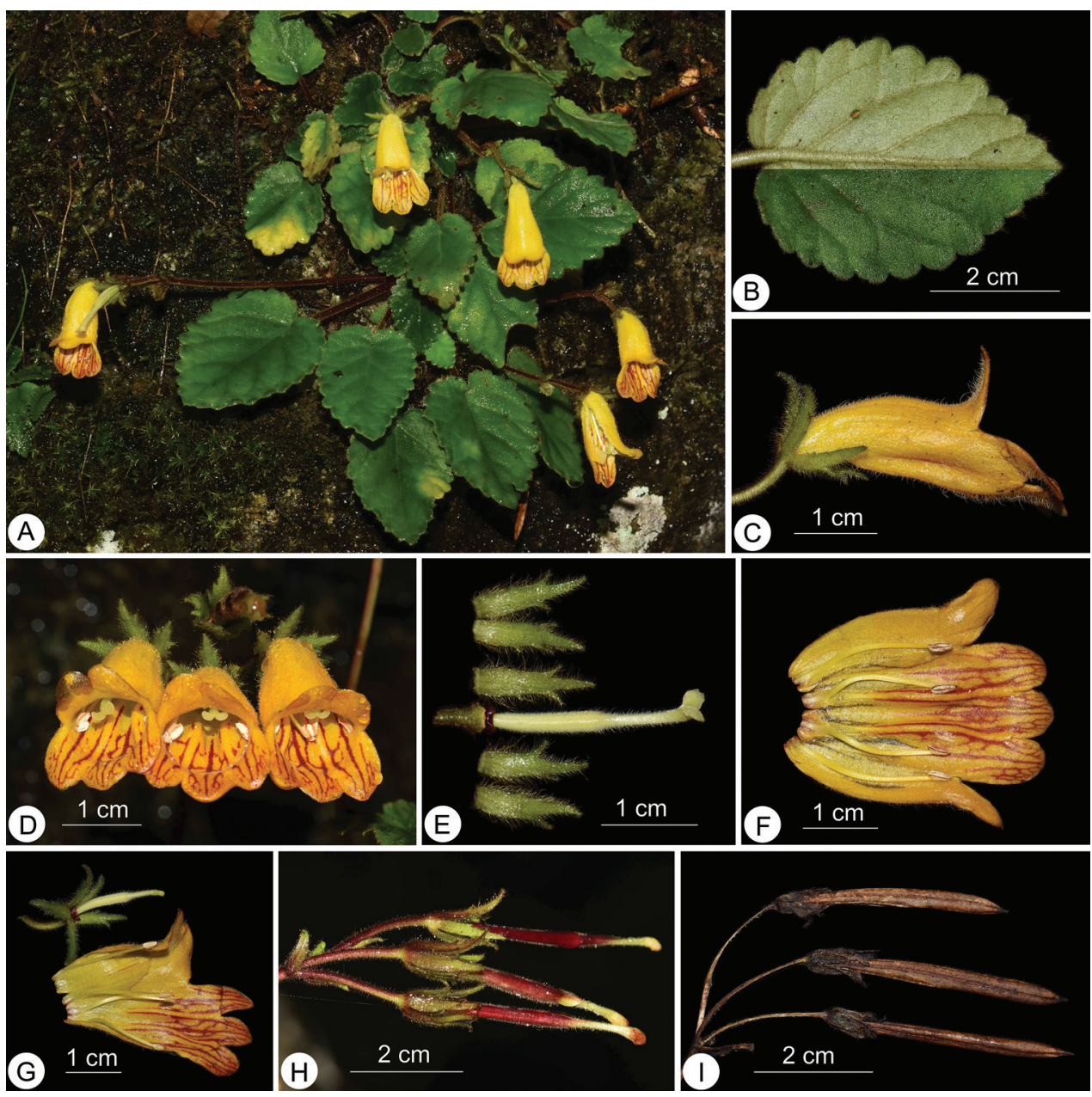

Figure 3. Oreocharis aimodisca Lei Cai, Z.L.Dao \& F. Wen, sp. nov. A habit B adaxial (lower half) and abaxial leaf surface (upper half) $\mathbf{C}$ side view of a flower $\mathbf{D}$ front view of flowers $\mathbf{E}$ pistil with disc and calyx $\mathbf{F}$ opened corolla showing stamens and staminode $\mathbf{G}$ opened corolla with pistil and calyx $\mathbf{H}$ fresh fruits I old capsules. Photographed by Lei Cai.

Etymology. The original specific epithet 'aimodisca' derives from the Greek ' $\alpha i \mu \alpha$ ' meaning blood red and 'Siøxos' meaning discus.

Vernacular name. The Chinese name of the new species is "Diān Dōng Mă Líng Jù Tái” (滇东马铃苣苔). The first two words, “Diān Dōng," mean east of Yunnan, the next four words, "Mă Líng Jù Tái," mean Oreocharis in Mandarin.

Conservation status. Based on our field investigations, the new species is currently only known from the type locality with two contiguous subpopulations, in total ca. one thousand mature individuals were present within $5000 \mathrm{~m}^{2}$ (AOO). Since no special surveys were carried out for delimiting its distribution and information about threats is not very clear, this species was provisionally considered to be Critically Endangered [CR B2(a)] in terms of the IUCN Red List Categories and Criteria (IUCN 2019). 
Table I. Morphological comparison of Oreocharis aimodisca sp. nov., O. longifolia and O. muscicola.

\begin{tabular}{|c|c|c|c|}
\hline Characters & O. aimodisca & O. longifolia & O. muscicola \\
\hline Leaf-blade & $\begin{array}{l}\text { oval to ovate, base cordate or } \\
\text { auriculate, margin crenate }\end{array}$ & $\begin{array}{l}\text { narrowly elliptic to oblanceolate, } \\
\text { base attenuate, margin serrulate }\end{array}$ & $\begin{array}{l}\text { narrowly elliptic to lanceolate, base } \\
\text { often slightly oblique, narrowly to } \\
\text { broadly cuneate, margin serrate to } \\
\text { serrate-crenate, sometimes doubly so }\end{array}$ \\
\hline Petiole & brown villous and pubescent & grey to brownish pubescent & densely rust-brown villous \\
\hline Peduncle & $\begin{array}{l}\text { densely brown villous and } \\
\text { pubescent }\end{array}$ & $\begin{array}{l}\text { sparsely brownish villous to } \\
\text { pubescent }\end{array}$ & $\begin{array}{l}\text { rust-brown villous and glandular- } \\
\text { pubescent }\end{array}$ \\
\hline Bract & $\begin{array}{l}\text { lanceolate to narrowly triangle, } \\
\text { outside brown pubescent margin } \\
\text { nearly entire to denticulate }\end{array}$ & $\begin{array}{l}\text { oblanceolate, outside pubescent, } \\
\text { margin entire }\end{array}$ & $\begin{array}{l}\text { lanceolate, outside rust-brown } \\
\text { villous, margin entire }\end{array}$ \\
\hline Calyx & $\begin{array}{l}\text { lobes linear-lanceolate or narrowly } \\
\text { triangular, both sides densely } \\
\text { pubescent, margin denticulate }\end{array}$ & $\begin{array}{c}\text { narrowly ovate, outside sparsely } \\
\text { brownish pubescent, inside } \\
\text { glabrous, margin entire }\end{array}$ & $\begin{array}{c}\text { lanceolate, outside sparsely white } \\
\text { pubescent and rust-brown villous, } \\
\text { margin entire }\end{array}$ \\
\hline Corolla & $\begin{array}{l}\text { outside densely pubescent, inside } \\
\text { puberulent in the throat and on } \\
\text { adaxial lobes }\end{array}$ & $\begin{array}{l}\text { outside sparsely glandular } \\
\text { puberulent, inside sparsely } \\
\text { glandular puberulent }\end{array}$ & $\begin{array}{l}\text { outside sparsely puberulent, inside } \\
\text { glandular pubescent }\end{array}$ \\
\hline Filaments & sparsely pubescent & glabrous & sparsely puberulent \\
\hline Anthers & oblong, separated & reniform, connected in pairs & reniform, connected in pairs \\
\hline Pistil & densely pubescent & glabrous & glabrous \\
\hline Disc & blood red & yellow & yellow-green \\
\hline
\end{tabular}

Taxonomic affinities. Oreocharis aimodisca is morphologically similar to O. longifolia and O. muscicola in the corolla yellow and coarsely tubular; however, it is different from the latter two species by the shape of the leaf blade, indumentum characters of the peduncle, pedicel, calyx, corolla and pistil and separated stamens. The comparison of morphological characters on related species is provided in Table 1.

\section{Oreocharis longipedicellata Lei Cai \& F.Wen, sp. nov.}

urn:Isid:ipni.org:names:77211927-1

Figures 4, 5

Diagnosis. Oreocharis longipedicellata morphologically resembles $O$. panzhouensis Lei Cai, Y.Guo \& F.Wen in its ovate leaf blade, yellow flower, four separated fertile stamens, oblong anthers and bilobed, flabellate stigma, but can be easily distinguished from this species in the peduncle $20-28 \mathrm{~cm}$ long, bract lanceolate to elliptic, margin denticulate, the calyx 5-lobed to the base, stamens adnate to corolla $3-4 \mathrm{~mm}$ from base and the pistil $1.5-2 \mathrm{~cm}$ long.

Type. China. Yunnan: Malipo County, Mengdong, on the surface of moist rocks (Cultivated in GCCC nursery, Guilin Botanical Garden, Chinese Academy of Sciences) in flower, 24 August 2019, Fang Wen WF190824-01 (holotype: KUN!, isotype: IBK!).

Description. Perennial herb, rhizome $0.8-2 \mathrm{~cm}$ long, $3-5 \mathrm{~mm}$ in diameter. Leaves $8-15$, basal, petiole $3.5-8.0 \mathrm{~cm}$ long, densely brown villous, leaf blade elliptic to ovate, $3.0-5.5 \times 2.4-4.5 \mathrm{~cm}$, adaxially densely pubescence, abaxially pubescent, densely brown villous along veins, lateral veins 3-6 on each side of midrib, apex rounded, base slightly oblique sometimes, cordate to auricula-cordate, margin cre- 


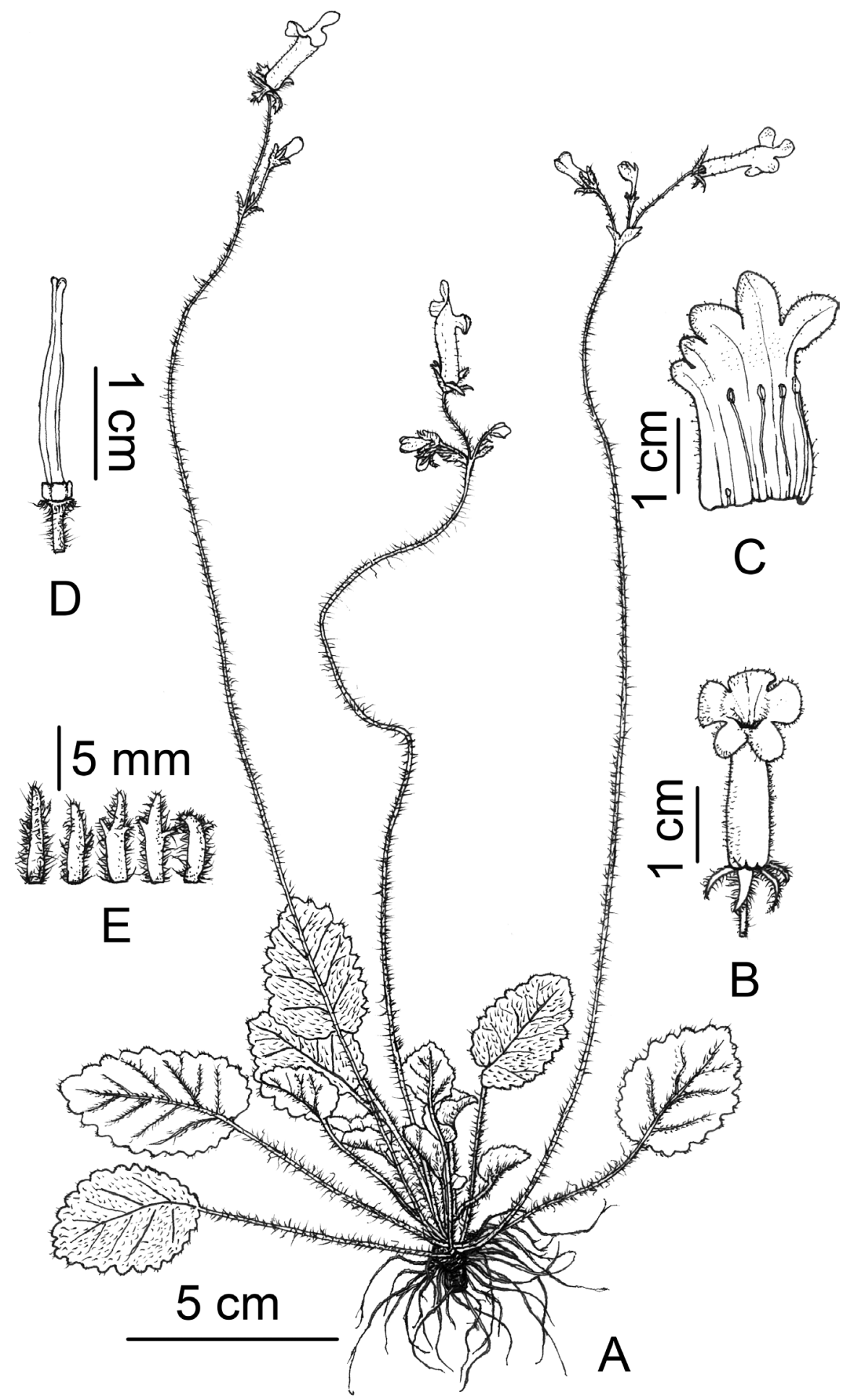

Figure 4. Oreocharis longipedicellata Lei Cai \& F.Wen, sp. nov. A habit B front view of flower $\mathbf{C}$ opened corolla showing stamens and staminode $\mathbf{D}$ pistil with disc $\mathbf{E}$ calyx lobes. Drawn by Xuan-Lin Zhu. 

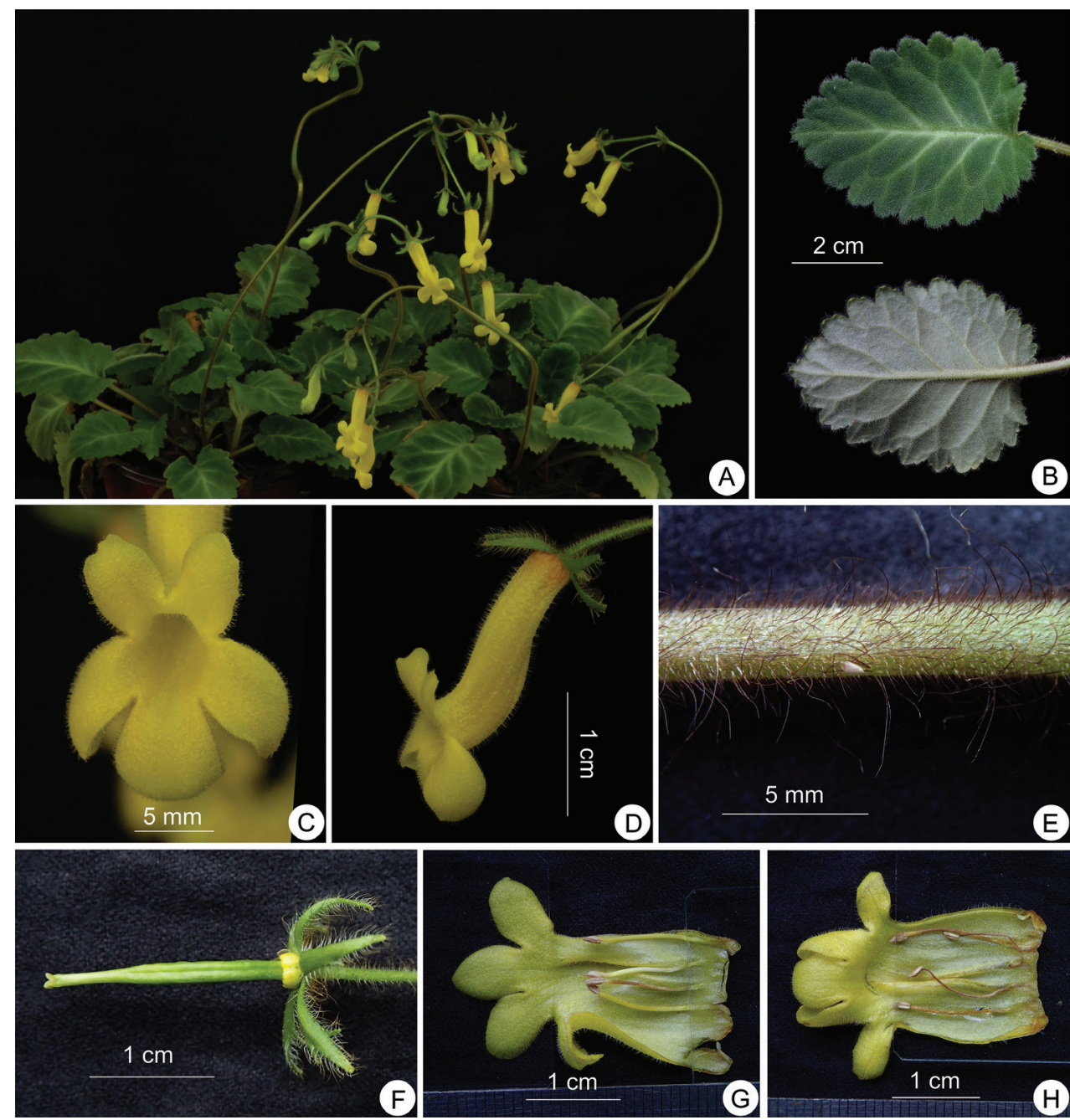

Figure 5. Oreocharis longipedicellata Lei Cai \& F. Wen, sp. nov. A plants cultivated in GBG B adaxial and abaxial leaf surface $\mathbf{C}$ front view of flowers $\mathbf{D}$ side view of a flower $\mathbf{E}$ petiole $\mathbf{F}$ pistil with disc and calyx $\mathbf{G}, \mathbf{H}$ opened corolla showing stamens and staminode. Photographed by Fang Wen.

nate, with brown villous. Cymes axillary 2-5, inflorescence 4-8-flowered; peduncle $20-28 \mathrm{~cm}$ long, brown villous; bracts 2 , lanceolate to elliptic, $10-12 \times 2.5-5.0 \mathrm{~mm}$, adaxially densely villous, abaxially glabrous, sometimes upper part pubescent, margin denticulate; pedicel $2.0-3.5 \mathrm{~cm}$ long, densely villous. Calyx 6-9 mm long, 5-lobed to the base, lobes triangular lanceolate to narrowly triangular, 6-9 mm long, 1.5-2 mm wide, outside brown villous, inside glabrous, margin denticulate. Corolla sigmoid, yellow, 2.2-2.8 cm long, outside pubescent and glandular-pubescent, inside glandular-pubescent in the throat and on adaxial lobes, tube cylindrical, slightly bent near the mouth, $1.8-2.2 \mathrm{~cm}$ long, 5-7 $\mathrm{mm}$ in diameter; limb 2-lipped; adaxial lip 2-lobed to near base, semicircular, lobes $4-5 \times 3.8-4.2 \mathrm{~mm}$, abaxial lip 3-lobed to 
Table 2. Morphological comparison between Oreocharis longipedicellata sp. nov. and O. panzhouensis.

\begin{tabular}{l|c|c}
\hline Characters & O. longipedicellata & O. panzhouensis \\
\hline Peduncle & 20-28 cm long & l.5-8 cm long \\
\hline Bract & lanceolate to elliptic, margin denticulate & linear to subulate, margin entire \\
\hline Calyx & $\begin{array}{c}\text { 5-lobed to the base, lobes lanceolate to narrowly trian- } \\
\text { gular, outside brown villous }\end{array}$ & $\begin{array}{c}\text { 5-lobed to the middle, lobes equal, broadly triangular, } \\
\text { outside pubescent and sparsely brown villous }\end{array}$ \\
\hline Corolla & $\begin{array}{c}\text { sigmoid, tube cylindrical, lobes reflexed outwards } \\
\text { slightly }\end{array}$ & $\begin{array}{c}\text { not sigmoid, tube campanulate, lobes not reflexed } \\
\text { outwards }\end{array}$ \\
\hline Ptamens & $\begin{array}{c}10-13 \mathrm{~mm} \text { long, adnate to corolla 3-4 mm from base } \\
\text { Pistil }\end{array}$ & $\begin{array}{c}\text { 5-10 mm long, adnate to corolla 5-6 } \\
\mathrm{mm} \text { from base }\end{array}$ \\
\hline
\end{tabular}

base, semicircular to oval, $6-8 \times 5-7 \mathrm{~mm}$. Stamens $4,1.0-1.3 \mathrm{~cm}$ long, adnate to corolla 3-4 mm from the base; filaments linear, glabrous; anthers oblong, 2-loculed, dehiscing longitudinally, connective glabrous; staminode 1, 0.6-1.0 mm long, inserted ca. $1 \mathrm{~mm}$ from the base. Disc ca. $1.5 \mathrm{~mm}$ high, yellow, margin undulate. Pistil $1.5-2.0 \mathrm{~cm}$ long, glabrous; ovary long cylindrical, $10-12 \mathrm{~mm}$ long; style $4-6 \mathrm{~mm}$ long; stigma bilobed, flabellate. Fruit unknown.

Phenology. Flowering from August to October; fruiting unknown.

Distribution and habitat. Oreocharis longipedicellata is currently known by only one population at the type locality, Mengdong, Malipo County, southeastern Yunnan, in the China and Vietnam border area. The species was observed to grow on the surface of moist rocks in the karst region.

Etymology. The specific epithet 'longipedicellata' refers to the relatively-long peduncle of the new species. This species has almost the longest pedicels in the genus Oreocharis.

Vernacular name. The Chinese name of the new species is "Cháng Gěng Mă Líng Jù Tái” (长梗马铃苣苔). The first two words, “Cháng Gěng," mean the long peduncle. The next four words mean Oreocharis in mandarin.

Conservation status. The new species could be endangered, but more data is needed to evaluate as the field distribution information is not sufficiently detailed.

Taxonomic affinities. Oreocharis longipedicellata most resembles recently published $O$. panzhouensis in the yellow flower, four separated stamens, calyx 5-lobed to the middle and stigma bilobed, flabellate. Nevertheless, it differs from the latter species in several other characteristics (see Table 2).

\section{Acknowledgements}

We are grateful to Ms. Xuan-Lin Zhu for the beautiful illustrations and processing the figures. Thanks also to Mr. Pin Zhang, Mr. Zheng-Yun Lu and Mr. Yu-Yang Lei for their help during the fieldwork. Special thanks to Stephen Maciejewski, The Gesneriad Society, Michael LoFurno, Adjunct Professor, Temple University, Philadelphia, USA and 
Zhi-Qian Zou for their editorial assistance. This study was financially jointly supported by the Science \& Technology Basic Resources Investigation Program of China (Grant no. 2017FY100100), Yunnan Science and Technology Innovation Team Program for PSESP (Plant Species with Extremely Small Populations) Conservation and Utilization (Grant No. 2019HC015), the National Natural Science Foundation of China (31860047), the Natural Science Foundation of Guangxi (2017GXNSFAA198006) and the Fund of Guangxi Key Laboratory of Plant Conservation and Restoration Ecology in Karst Terrain (19-050-6).

\section{References}

Cai L, Guo Y, Zhang RM, Dao ZL, Wen F (2019) Oreocharis panzhouensis (Gesneriaceae), a new species from karst regions in Guizhou, China. Phytotaxa 393(3): 287-291. https:// doi.org/10.11646/phytotaxa.393.3.5

Cai L, Huang H, Dao ZL, Wu ZK (2017) Oreocharis parviflora, a new species of Gesneriaceae from northwestern Yunnan, China. Phytotaxa 329(2): 167-172. https://doi.org/10.11646/ phytotaxa.329.2.7

Chen WH, Nguyen QH, Chen RZ, Nguyen TH, Nguyen SK, Nguyen VT, Möller M, Middleton DJ, Shui YM (2018) Two new species of Oreocharis (Gesneriaceae) from Fan Si Pan, the highest mountain in Vietnam. PhytoKeys 94: 95-106. https://doi.org/10.3897/phytokeys.94.21329

Chen WH, Shui YM, Möller M (2014) Two new combinations in Oreocharis Benth. (Gesneriaceae) from China. Candollea 69(2): 179-182. https://doi.org/10.15553/c2014v692a10

Do VT, Wei YG, Wen F (2017) Oreocharis caobangensis (Gesneriaceae), a new species from Cao Bang Province, northern Vietnam. Phytotaxa 302(1): 65-70. https://doi.org/10.11646/ phytotaxa.302.1.6

Guo ZY, Li ZY, Xiang XG (2018) Oreocharis duyunensis (Gesneriaceae), a new species from Guizhou, China. Nordic Journal of Botany 36(9): e01514. https://doi.org/10.1111/njb.01514

IUCN (2019) Guidelines for Using the IUCN Red List Categories and Criteria. Ver. 14. Prepared by the Standards and Petitions Subcommittee of the IUCN Species Survival Commission. http://cmsdocs.s3.amazonaws.com/RedListGuidelines.pdf

Li JM, Li ZM (2015) Oreocharis brachypodus (Gesneriaceae), a new taxon from Guizhou, China. Phytotaxa 204(4): 296-299. https://doi.org/10.11646/phytotaxa.204.4.6

Li ZY, Wang YZ (2005) Plants of Gesneriaceae in China. Henan Science \& Technology Publishing House, Zhengzhou, Henan, 14-47.

Middleton DJ, Weber A, Yao TL, Sontag S, Möller M (2013) The current status of the species hitherto assigned to Henckelia (Gesneriaceae). Edinburgh Journal of Botany 70(3): 385-404. https://doi.org/10.1017/S0960428613000127

Möller M (2015) Transfer of Tremacron hongheense to Oreocharis (Gesneriaceae). Phytotaxa 239(3): 295-296. https://doi.org/10.11646/phytotaxa.239.3.12

Möller M, Atkins HJ, Bramley GL, Middleton DJ, Baines R, Nguyen VD, Bui HQ, Barber S (2018) Two new species of Oreocharis (Gesneriaceae) from northern Vietnam. Edinburgh Journal of Botany 75(3): 309-319. https://doi.org/10.1017/S0960428618000148 
Möller M, Chen WH, Shui YM, Atkins H, Middleton DJ (2014) A new genus of Gesneriaceae in China and the transfer of Briggsia species to other genera. Gardens' Bulletin (Singapore) 66: 195-205.

Möller M, Middleton DJ, Nishii K, Wei YG, Sontag S, Weber A (2011) A new delineation for Oreocharis incorporating an additional ten genera of Chinese Gesneriaceae. Phytotaxa 23(1): 1-36. https://doi.org/10.11646/phytotaxa.23.1.1

Möller M, Nampy S, Janeesha AP, Weber A (2017) The Gesneriaceae of India: Consequences of updated generic concepts and new family classification. Rheedea 27(1): 23-41. https:// doi.org/10.22244/rheedea.2017.27.1.5

Pan B, Tang GD, Do TV, Maciejewski S, Deng CL, Wen F (2019) Oreocharis tetrapterus (Gesneriaceae), a new species from East Guangxi, China. PhytoKeys 131: 83-89. https:// doi.org/10.3897/phytokeys.131.35434

Wang WT, Pan KY, Li ZY (1990) Gesneriaceae. In: Wang WT (Ed.) Flora Reipublicae Popularis Sinicae (Vol. 69). Science Press, Beijing, 141-271.

Wang WT, Pan KY, Li ZY, Weitzman AL, Skog LE (1998) Gesneriaceae. In: Wu ZY, Raven PH (Eds) Flora of China (Vol. 18). Science Press, Beijing \& Missouri Botanical Garden Press, St. Louis, 254-401.

Wen F, Li S, Xin ZB, Fu LF, Hong X, Cai L, Qin JQ, Pan B, Pan FZ, Wei YG (2019) The updated plant list of Gesneriaceae in China under the new Chinese naming rules. Guangxi Sciences 26(1): 37-63.

Wen F, Wei YG, Fu LF, Xin ZB, Li S, Huang ZJ, Meng DC (2014 onward) The Checklist of Gesneriaceae in China. [Free download from] http://gccc.gxib.cn/about-46.aspx

Xuyen DT, Phuong VX, Hoan HV, Duc NA (2016) Genus Opithandra B.L. Burtt and Species Opithandra dinghushanensis W.T. Wang as new records for the flora of Vietnam from Bac Huong Hoa Nature Reserve, Quang Tri Province. VNU Journal of Science: Natural Sciences and Technology 32(1S): 142-146.

Yang LE, Cen HF, Sun H, LoFurno M, Maciejewski S, Goretsky WJ, Wen F (2019) Oreocharis rubrostriata (Gesneriaceae), a new species from Guangxi, China. Kew Bulletin 74(23): 1-5. https://doi.org/10.1007/s12225-019-9810-9 